\title{
Cosmologia e Adaptação Ecológica: o caso dos apliques-mamíferos das estearias maranhenses
}

\author{
Alexandre Guida Navarro ${ }^{a}$ \\ José de Sousa e Silva Júnior ${ }^{\mathrm{b}}$
}

As sociedades ameríndias estiveram envolvidas em complexos sistemas adaptativos e cosmológicos, cujos mitos estão povoados de animais das mais diversas espécies. No entanto, pouco se explorou a relação entre estes animais com os materiais arqueológicos. Este artigo apresenta uma coleção de artefatos das estearias maranhenses com representação de animais que foram identificados através de sues atributos biológicos em nível de espécie e depois comparados com suas funções sociais a partir de mitos pan-amazônicos. Um dos resultados é uma crítica ao perspectivismo ameríndio, uma vez que indígenas que habitaram as palafitas pré-coloniais do Maranhão preocuparam-se em identificar as diferentes espécies de seu nicho ecológico. Propõe-se, também, que a Zoologia é indispensável para o estudo da representação de animais nos artefatos arqueológicos.

Cultura material, Mitos amazônicos, Estearias, Crítica ao perspectivismo.

Shamans transform, under the effects of psychotropic drugs, into jaguars as jaguars mutate into humans. Thus when a shaman becomes a jaguar he ripens the fruits through the emanations of his fertility.

(Goldman 1963:262, sobre os Paniwa, noroeste da Amazônia).

a Professor no Departamento de História (UFMA) e Coordenador do Laboratório de Arqueologia (LARQ/UFMA). Bolsista Produtividade em Pesquisa (CNPq). Email: altardesacrificios@yahoo.com.br.

b Pesquisador Programa de Pós-Graduação em Zoologia (ICB/Museu Paraense Emilio Goeldi). Email: cazuza.junior@gmaíl.com. 


\section{Por uma biologia nos estudos arqueológicos}

Homens e animais sempre estiveram envolvidos em complexos sistemas adaptativos e cosmológicos. As cosmologias ameríndias constituem um amplo espectro de análise a partir da Antropologia utilizando o método etnográfico (Lévi-Strauss 2008 [1958]; Lagrou 2007). Conceitos como representação (Lagrou 2007) perderam espaço pelo viés estático da análise, dando lugar a conceitos mais dinâmicos e plurais da cultura, como o de agência (Gell 1998) e o perspectivismo ameríndio (Viveiros de Castro 2002). No entanto, no que tange à Arqueologia, conceitos formais e descritivos (Gomes 2012) ainda são necessários, uma vez que a análise arqueológica baseia-se, ainda em grande parte, na leitura dos atributos tecnológicos da cultura material (Hodder 1982).

Arqueólogos estão de acordo que os mitos relatados por etnógrafos também refletem na arte ameríndia, uma vez que seus elementos estruturais, como certos animais, foram representados na parafernália ritual, sobretudo nos vasilhames cerâmicos. A identificação destes animais associados às práticas cosmológicas e/ou cosmopolíticas são uma prática recorrente estre os especialistas no tema na Arqueologia brasileira (Roosevelt 1988; Gomes 2001, 2012; Schaan 2004; Barreto 2008; Navarro 2017).

Apoiado pela evidência etnográfica e arqueológica, muitos estudiosos defendem uma cosmologia pan-amazônica, cujos traços das concepções de vida indígena puderam ser compartilhados desde as terras altas e baixas da Colômbia até a foz do rio Amazonas. Destacamse, assim, as ontologias de animais, caracterizadas pelo perspectivismo, predação e ação xamânica (Reichel-Dolmatoff 1976; Roe 1982; Roosevelt 1988; Viveiros de Castro 2002; Descola 2005; Gomes 2012). Por outro lado, poucos estudiosos preocuparam-se com as características biológicas sistemáticas das espécies apresentadas em seus trabalhos, em detrimento de uma suposta uniformidade conceitual que leva a considerar o animal somente quanto a sua roupagem. Este estudo indica que é necessário abordar outras metodologias. 
Arqueólogos e antropólogos deveriam atentar-se mais com as espécies que analisam no que tange às ontologias animais. Neste sentido, é fundamental que suas análises sejam compartilhadas com zoólogos. Haveria algum traço específico destes animais que poderiam esclarecer aspectos cosmológicos e que não são visíveis aos olhares antropológicos e arqueológicos? Este artigo discute esta proposição e traz inferências para o estudo das cosmologias indígenas das terras baixas da América do Sul, neste caso as estearias do Maranhão, à luz da cooperação entre zoólogos e arqueólogos.

\section{As estearias e seu nicho ecológico}

As estearias são sítios arqueológicos formados pela presença de construção de palafitas nas vivendas (Lopes 1924; Navarro 2013, 2017, 2018a, 2018b; Leite Filho 2016) (Figura 1). Estes sítios estão localizados na Baixada Maranhense, a oeste da capital São Luís, em uma região estuarina formada pela presença de duas bacias hidrográficas, a do rio Turiaçu e a do rio Pindaré-Mearim. As aldeias foram erigidas dentro dos canais dos rios ou em lagos formados pelo transbordamento do leito destes rios na época da cheia. A farta alimentação lacustre e suas áreas de captação de recursos podem estar ligadas à escolha deste ambiente aquático para a construção das moradias (Navarro 2017, 2018a)

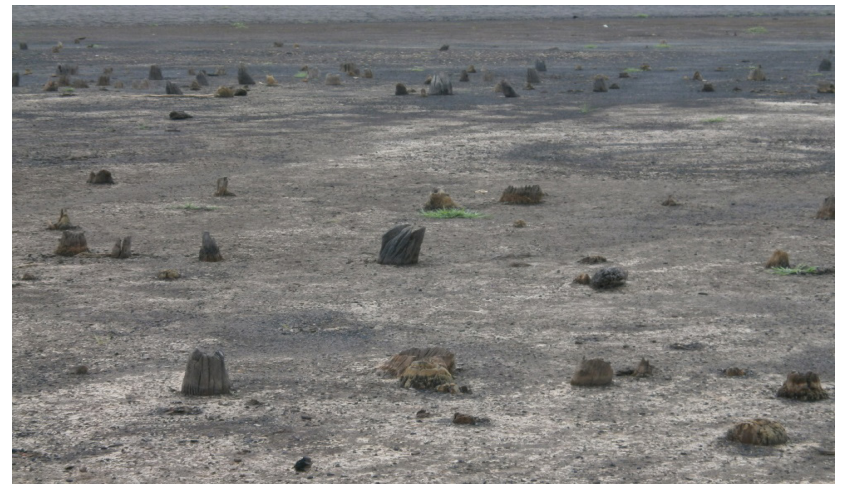

Figura 1. Um sítio de palafitas na época da seca. Fotografia: Alexandre Navarro. 
A região da Baixada Maranhense é parte da Área de Endemismo Belém (sensu Cracraft 1985; Cardoso da Silva \& Oren 1996; Cardoso da Silva et al. 2005), localizada na zona fisiográfica do leste do Pará e oeste do Maranhão, com uma área de 243.000 $\mathrm{km}^{2}$, sendo limitada a oeste pelo rio Tocantins e a leste pelo rio Pindaré (Almeida \& Vieira 2010). Embora ainda não exista um levantamento completo da diversidade de mamíferos nesta Área de Endemismo, pode-se perceber, com base nas distribuições geográficas descritas em compilações de dados (Emmons \& Feer 1997; Eisenberg \& Redford 1999) e inventários mais localizados (Pine 1973; Oliveira et al.,2007; Stone et al. 2009; Silva-Júnior et al. 2010), que esta é uma região rica em espécies de mamíferos. Os inventários de Oliveira et al. (2007) na Amazônia maranhense e Silva-Júnior et al. (2010) no litoral amazônico indicam que a região da Baixada Maranhense constitui o segmento com mais baixa amostragem de toda a Área de Endemismo Belém. Apesar disso, espera-se que uma grande parcela das espécies de mamíferos desta Área de Endemismo esteja presente na região, uma vez que a mesma está localizada entre pontos de registro empírico e também porque as espécies em questão não apresentam maiores restrições aos habitats localmente disponíveis.

Os sítios arqueológicos investigados na Baixada Maranhense evidenciam uma ocupação humana de longa duração na região escolhida para residir. As datações realizadas pelo Laboratório de Arqueologia (LARQ) da UFMA colocam as datas entre o início da era cristã até o ano de 1100 d.C. Depois desta época os povos que ali viviam colapsaram ou se mudaram para outros locais. À época da chegada dos europeus no século XVI, já não existiam sociedades vivendo em palafitas na região. Nem mesmo os indígenas com os quais os cronistas coletaram informações, como Guajajara e Canela, mencionaram-nas.

O material arqueológico das estearias é caracterizado por duas predileções tecno-decorativas nos vasilhames cerâmicos: pintura preta 
e vermelha com motivos geométricos em fundo branco e apliques zoomorfos. A fauna é bastante complexa, englobando espécies de anfíbios, aves, peixes e mamíferos, estes últimos destacando-se na iconografia quanto a sua decoração plástica. Houve, portanto, uma predileção pela representação de mamíferos em forma de apliques modelados na decoração dos vasilhames cerâmicos.

\section{Procedimento de identificação das peças}

O material arqueológico foi coletado no âmbito do projeto de pesquisa intitulado 'O povo das águas: carta arqueológica das estearias da porção centro-norte da Baixada Maranhense', realizado pelo Laboratório de Arqueologia, da Universidade Federal do Maranhão (LARQ/UFMA). As peças de cerâmica aqui apresentadas foram resgatadas em cinco estearias localizadas na região do rio Turiaçu, município de Santa Helena, Maranhão: Armíndio (ARM), Caboclo (CAB), Boca do Rio (BR) e Jenipapo (JEN) (Navarro et al., 2017).

Selecionaram-se 16 peças de cerâmica com motivos zoomórficos constituindo representações de mamíferos. O processo de identificação dos táxons foi realizado ao longo de dois anos, envolvendo exames periódicos das imagens para familiarização com os traços morfológicos presentes nas esculturas. Além disso, as imagens foram examinadas por outros mastozoólogos para discussão das informações contidas nas peças.

A identificação dos táxons foi baseada no pressuposto de que os escultores retrataram a fauna local. Os caracteres morfológicos representados nas peças foram comparados com os caracteres diagnósticos descritos para as ordens, famílias e gêneros de mamíferos presentes na Área de Endemismo Belém. Nos casos em que a identificação na categoria do gênero foi possível, a área do sítio arqueológico foi plotada sobre o mapa de distribuição geográfica daquele gênero. Quando apenas uma espécie do gênero em questão ocorria na região investigada, esta pode ser seguramente identificada. 


\section{Resultados}

De maneira geral, as representações de mamíferos na cerâmica das estearias da Baixada Maranhense é extensa, mas a identificação dos táxons é agravada pelo desgaste sofrido pelas peças durante o evento que resultou em descarte das mesmas e pela ação da intempérie ao longo do tempo. A maioria representa apenas a cabeça do animal aplicada a uma peça maior. A moldagem das peças sofreu a influência das habilidades manuais individuais e da percepção, por parte dos escultores, do conjunto de traços morfológicos de cada táxon retratado. Em algumas peças as imagens de mamíferos são reconhecíveis quando observadas de apenas uma perspectiva e, em outras, por um ou poucos caracteres morfológicos. Contudo, grande parte das esculturas apresenta traços que assinalam caracteres diagnósticos dos táxons. Algumas foram identificadas com relativa facilidade, enquanto outras demandaram mais tempo e sessões de exames e comparações.

Foram identificadas 16 peças contendo esculturas de mamíferos representantes das ordens Cingulata, Pilosa, Primates, Carnivora, Artiodactyla e Rodentia. Destas, duas (BR 10309 e BR 10237) foram classificadas apenas na categoria da ordem, a primeira como uma representação de carnívoro (Carnivora) com base nas orelhas curtas e arredondadas, focinho curto e garras das patas anteriores em destaque; a segunda como uma representação de roedor (Rodentia) com base na face em perspectiva lateral. Duas peças (BR 0034 e BR 10202) foram identificadas apenas na categoria da família (Tayassuidae) com base na morfologia da cabeça e narinas. As demais foram identificadas no nível da espécie, perfazendo um total de 13 espécies pertencentes a 13 gêneros, 11 famílias e seis ordens.

Após o processo de identificação, dados sobre taxonomia, caracteres morfológicos, modos de vida e distribuição geográfica foram compilados para compor uma lista comentada dos grupos representados, dada a seguir. As peças da coleção arqueológica da UFMA que representam cada táxon são discriminadas, descrevendo-se os respectivos números de registro e os critérios usados para identificação das mesmas. 


\section{ORDEM Cingulata Illiger, 1811 (tatus)}

Família Dasypodidae Gray, 1821

Tatu-canastra - Priodontes maximus (Kerr, 1792)

O tatu-canastra (Priodontes maximus) é exclusivamente noturno, largamente fossorial e cavador eficiente, utilizando para isso as grandes garras em forma de cimitarra (Eisenberg \& Redford 1999). Estes animais são capazes de explorar uma grande variedade de habitats, incluindo planícies de inundação (Marinho-Filho \& Medri 2008; Chiarello et al. 2015). Priodontes maximus é uma espécie de ampla distribuição geográfica, ocorrendo na maior parte da América do Sul cisandina (Gardner, 2005; Wetzel et al., 2007). A peça ARM 10320 (Figura 2) foi identificada como P. maximus com base no focinho levemente encurvado para baixo, orelhas medianamente proeminentes, e representação estilizada de placas concêntricas na parte anterior da carapaça.

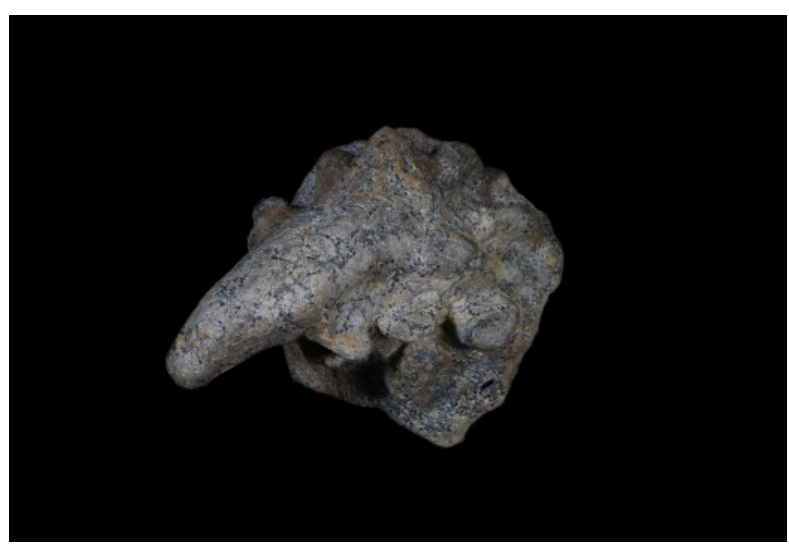

Figura 2. Tatu-canastra. Fotografia: Fábio Mata.

\section{Tatu-peba - Euphractus sexcinctus (Linnaeus 1758)}

Os tatus-peba são principalmente diurnos. Apesar de mostrarem preferência por ambientes de vegetação aberta (Eisenberg \& Redford 1999; Marinho-Filho \& Medri 2008), esses animais são capazes de ex- 
plorar uma gama de habitats, incluindo áreas florestadas (Silva-Júnior et al. 2001; Silva et al. 2015). Euphractus sexcinctus é uma espécie de ampla distribuição geográfica, ocorrendo na maior parte da América do Sul cisandina (Gardner 2005; Wetzel et al. 2007). A peça CAB 0011 (Figura 3) foi identificada como Euphractus sexcinctus com base no focinho mais curto e apenas levemente encurvado, nenhum destaque às orelhas, e nas placas concêntricas muito arredondadas na parte anterior da carapaça.

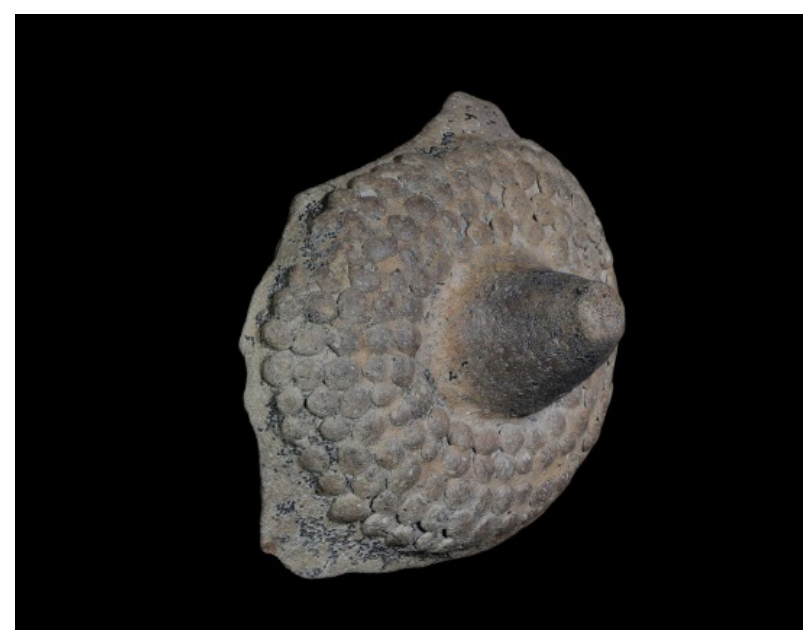

Figura 3. Tatu-peba. Fotografia: Fábio Mata.

\section{ORDEM Pilosa Flower, 1883 (preguiças)}

\section{Família Bradypodidae Gray, 1821}

Preguiça-de-bentinho - Bradypus variegatus Schinz, 1825

Bradypus variegatus é uma espécie de ampla distribuição geográfica, ocorrendo na maior parte da faixa tropical da América do Sul, em ambos os lados da Cordilheira dos Andes (Eisenberg \& Redford 1999; Gardner 2007; Xavier et al. 2015). A peça ARM 271 foi identificada como B. variegatus com base na morfologia da face, típica do gê- 
nero Bradypus. O rostro é menos desenvolvido que o das preguiças do gênero Choloepus devido à ausência do osso prenasal. A única espécie de Bradypus presente na região da Baixada Maranhense é B. variegatus.

\section{Família Megalonychidae Gervais, 1855}

\section{Preguiça-real - Choloepus didactylus Illiger, 1811}

Choloepus didactylus é uma das duas espécies atuais de preguiças-reais (Adam, 1999; Medri et al. 2006; Gardner \& Napples 2007). Esta espécie ocorre a leste dos Andes desde o sul da Colômbia, Venezuela, Guianas, Equador, Peru, e Amazônia brasileira até o oeste do Maranhão (Adam 1999; Medri et al. 2006; Miranda et al. 2015; Chiarello \& Plese 2014), alcançando também o norte de Mato Grosso (Trinca et al. 2006). A peça ARM 10388 (Figura 4) foi identificada como Choloepus didactylus com base na morfologia da face, com o formato do rosto sugerindo a presença do osso prenasal, apesar da extremidade da pata esquerda sugerir, de maneira não muito clara, a presença de três dedos. A única espécie de Choloepus presente na região da Baixada Maranhense é C. didactylus.

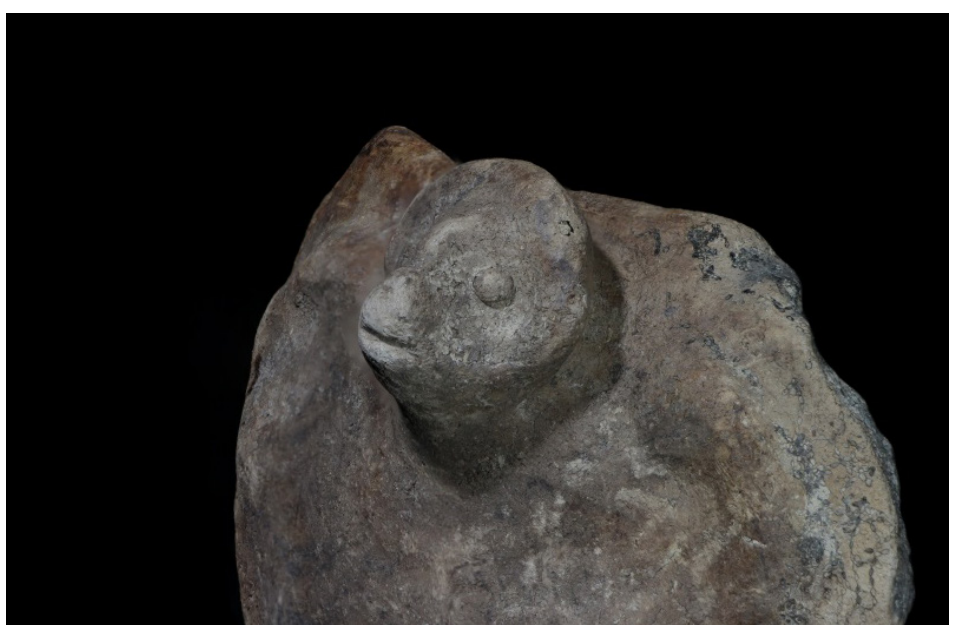

Figura 4. Preguiça-real. Fotografia Fábio Mata. 
ORDEM Primates Linnaeus, 1758 (saguis e macacos) Família Cebidae Bonaparte, 1831

Macaco-de-cheiro, mão-de-ouro - Saimiri collinsi Osgood, 1916

Os macacos-de-cheiro apresentam uma clara preferência por habitats alagáveis ou de margens de corpos d'água (Baldwin \& Baldwin 1981; Baldwin 1985). Saimiri collinsi é uma espécie de ampla distribuição geográfica, ocorrendo na região situada ao sul do rio Amazonas (incluindo o arquipélago do Marajó), desde o rio Tapajós até parte do Cerrado, no Maranhão (Silva-Júnior et al. 2015; Mercês et al. 2017). Esta é a única espécie de Saimiri presente na região da Baixada Maranhense. A peça BR 001 (Figura 5) foi identificada como Saimiri collinsi com base no tamanho e forma das órbitas, com os arcos superciliares ressaltados, na sugestão de mancha circumbucal, e na morfologia da boca.

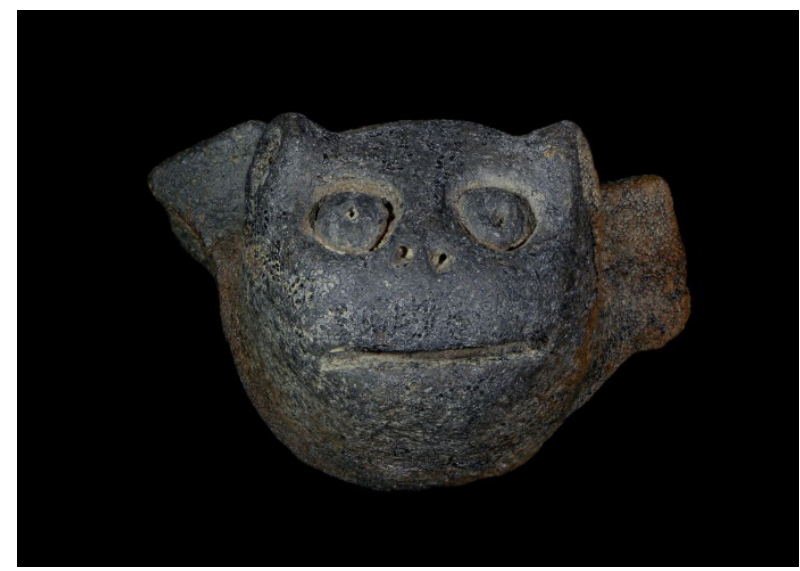

Figura 5. Macaco-de-cheiro. Fotografia: Fábio Mata.

Família Aotidae Elliot, 1913

Macaco-da-noite - Aotus infulatus (Kuhl, 1820)

Os animais deste gênero são facilmente identificáveis devido a uma série de caracteres morfológicos conspícuos, especialmente os 
grandes olhos adaptados para captar a luz no ambiente noturno (Hill 1960; Hershkovitz 1983). São quase exclusivamente arborícolas, ocorrendo em diversos tipos de florestas na Amazônia, incluindo florestas alagáveis (Wright 1981; Emmons \& Feer 1997; Eisenberg \& Redford 1999), e também em parte do Cerrado (Silva-Júnior \& Fernandes 1999; Pinto et al. 2015). Aotus infulatus é uma espécie de ampla distribuição geográfica, ocorrendo nos estados do Amapá, Mato Grosso, Maranhão, Pará, Tocantins e Piauí (Silva-Júnior et al., 1995; Silva-Júnior \& Fernandes 1999; Pinto et al. 2015). A peça ARM 061 (Figura 6) foi identificada como Aotus infulatus com base na morfologia da cabeça e orelhas, no tamanho e forma das órbitas, e no nariz pequeno, caracteristicamente pronunciado.

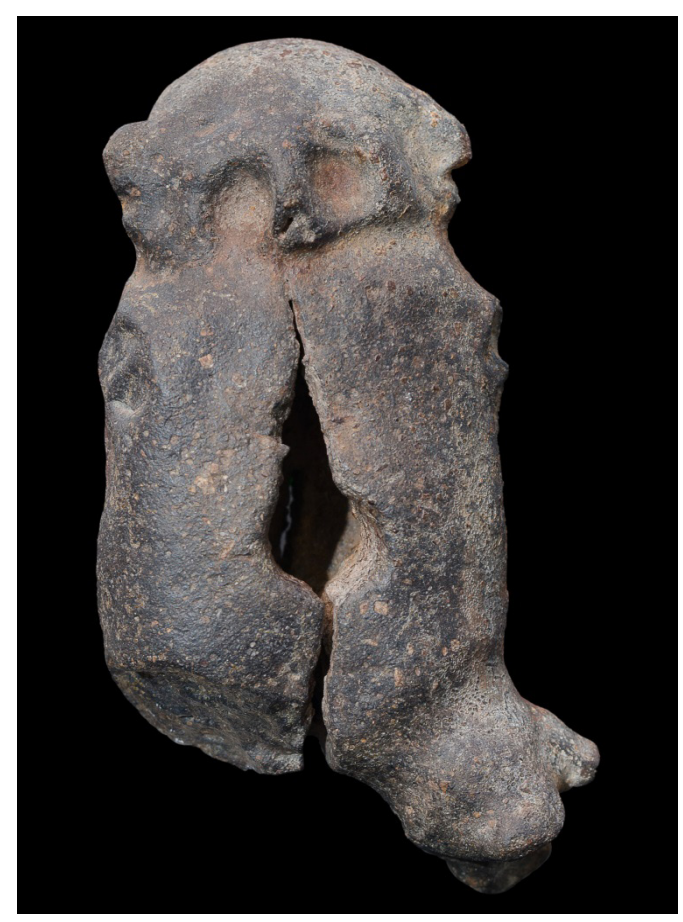

Figura 6. Macaco-da-noite. Fotografia: Fábio Mata. 


\section{ORDEM Carnivora Bowdich, 1821 (carnívoros)}

\section{Família Mustelidae Fischer, 1817}

\section{Irara - Eira barbara (Linnaeus, 1758)}

Os animais deste gênero apresentam uma combinação de membros curtos com corpo e cauda alongados (Presley 2000; Cheida et al. 2006). As iraras são consideradas carnívoros de tamanho médio (Cheida et al. 2006). São predominantemente arborícolas, ocorrendo em diversos tipos de florestas, incluindo áreas alagáveis (Presley 2000; Rodrigues et al. 2013). São animais onívoros oportunistas e predadores ativos (Presley, 2000; Cheida et al. 2006; Rodrigues et al. 2013; Cuarón et al. 2016). Eira barbara é uma espécie de ampla distribuição geográfica, ocorrendo na maior parte das Américas Central e do Sul (Rodrigues et al. 2013; Cuarón et al. 2016). A peça BR 10311 foi identificada como Eira barbara com base na morfologia da cabeça, especialmente as orelhas e focinho. Estes traços morfológicos são mais evidentes em perspectiva frontal.

\section{Família Procyonidae Gray, 1825}

\section{Quati - Nasua nasua (Linnaeus, 1766)}

Esta espécie é facilmente identificável devido à combinação de cabeça larga com focinho longo e estreito, bastante saliente e de grande mobilidade (Cheida et al. 2006). Nasua nasua é uma espécie de ampla distribuição geográfica, ocorrendo na maior parte da América do Sul cisandina (Beisiegel \& Campos,2013; Emmons \& Helgen 2013). As peças BR 0032 e BR 10215 (Figura7) foram identificadas como Nasua nasua com base na morfologia das orelhas e da cabeça larga com focinho afilado. Contudo, na peça BR 10215 a espécie pode ser identificada apenas em perspectiva dorsal, uma vez que a parte lateral da boca foi esculpida com morfologia crocodiliana. 


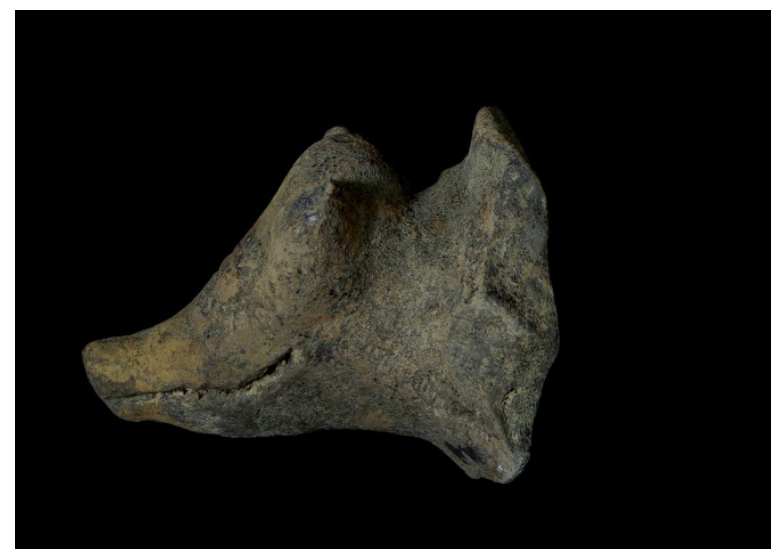

Figura 7. Quati com boca crocodiliana. Fotografia: Fábio Mata.

\section{Guaxinim - Procyon cancrivorus (Cuvier, 1798)}

Os guaxinins são considerados carnívoros de porte médio (Cheida et al. 2006). São frequentemente encontrados em habitats alagáveis ou de margens de corpos d'água (Cheida et al. 2013; Reid et al. 2016). Procyon cancrivorus é uma espécie de ampla distribuição geográfica, ocorrendo na maior parte das Américas Central e do Sul (Cheida et al. 2013; Reid et al. 2016). A peça JEN 0014 (Figura 8) foi identificada como Procyon cancrivorus com base na morfologia da cabeça, especialmente as orelhas proeminentes, olhos grandes e focinho mais curto e afilado.

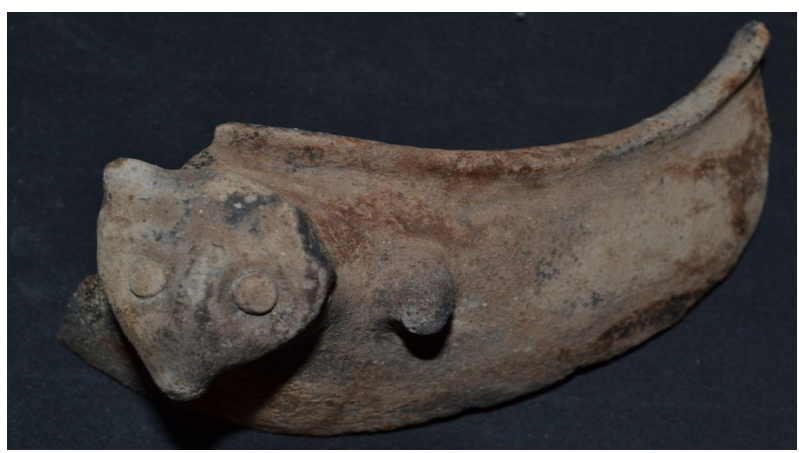

Figura 8. Guaxinim. Fotografia: Alexandre Navarro. 


\section{Família Canidae Fischer, 1817}

\section{Cachorro-do-mato-vinagre - Speothos venaticus (Lund, 1842)}

Carnívoro de tamanho médio, com preferência por habitats florestais alagáveis ou de margens de corpos d'água (Eisenberg \& Redford 1999; Cheida et al. 2006; Jorge et al. 2016), mas ocorrendo também em ambientes menos úmidos (Emmons \& Feer 1997; DeMatteo et al., 2011). Speothos venaticus é uma espécie de ampla distribuição geográfica, ocorrendo em grande parte da América do Sul (Cheida et al., 2006; DeMatteo et al. 2011; Jorge et al. 2016). As peças BR 0055 e BR 0056 (Figura 9) foram identificadas como Speothos venaticus com base na morfologia da cabeça e do corpo alongado, com focinho, cauda e membros curtos.

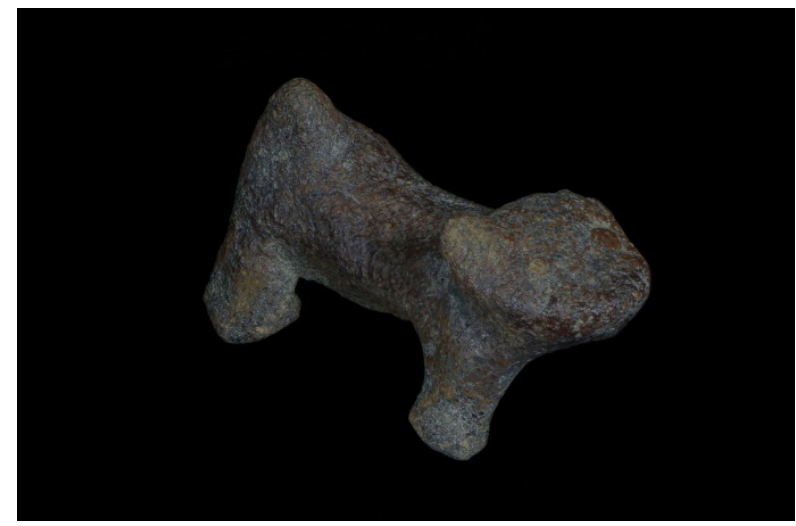

Figura 9. Cachorro-do-mato-vinagre. Fotografia: Fábio Matta.

\section{ORDEM Artiodactyla Owen, 1848 (porcos e veados)}

Família Tayassuidae Palmer, 1897

Caititu - Pecari tajacu (Linnaeus, 1758) ou queixada - Tayassu pecari (Link, 1795)

Os porcos selvagens dos gêneros Pecari e Tayassu são táxons de ampla distribuição geográfica, ocorrendo na maior parte das Américas 
Central e do Sul, além de parte da América do Norte (Grubb 2005; Tiepolo \& Tomas 2006). Os caracteres representados nas peças BR 0034 e BR 10202 são comuns a ambos os gêneros e espécies, tendo permitido a identificação apenas no nível da família (Tayassuidae). A peça BR 0034 (Figura 10) foi identificada com base na morfologia da parte frontal da cabeça (testa), e a peça BR 10202 com base na morfologia das narinas.

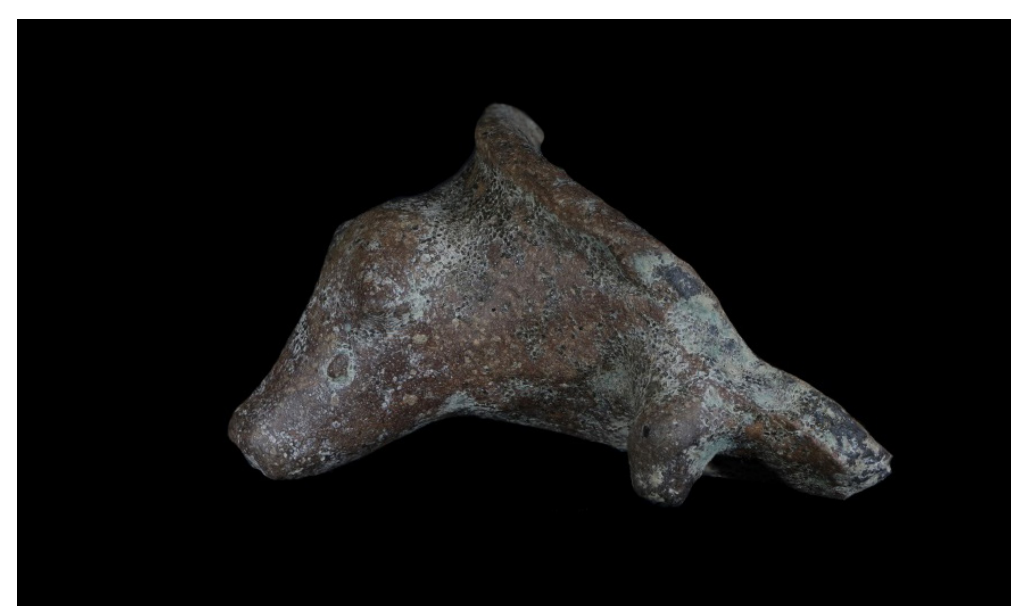

Figura 10. Caititu. Fotografia: Fábio Mata.

\section{ORDEM Rodentia Bowdich, 1821 (roedores)}

\section{Família Caviidae Fischer, 1917}

Capivara - Hydrochoerus hydrochaeris (Linnaeus, 1766)

Espécie de ampla distribuição geográfica, a qual abrange a maior parte da América do Sul cisandina, estendendo-se desde o norte da Colômbia até o norte da Argentina e Uruguai (Dunnum 2015). A espécie apresenta hábitos semiaquáticos, podendo ocorrer em campos inundáveis, pântanos, estuários e ao longo de rios e canais (Em- 
mons \& Feer 1997; Eisenberg \& Redford 1999). A peça ARM 059 foi identificada como Hydrochoerus hydrochaeris com base no focinho aproximadamente quadrangular (especialmente em perspectiva lateral), orelhas pequenas no alto da cabeça, e olhos alongados.

\section{Família Dasyproctidae Bonaparte, 1838}

\section{Cutia - Dasyprocta primnolopha Wagler, 1831}

Os limites entre as distribuições geográficas das espécies de cutias ainda não são bem conhecidos (Patton \& Emmons, 2015). Contudo, existe um consenso entre os autores (Iack-Ximenes, 1999; Oliveira \& Bonvicino, 2006; Bonvicino et al., 2008; Patton \& Emmons, 2015; Catzeflis et al., 2013) no sentido de reconhecerem D. primnolopha como a única espécie de Dasyprocta presente na região da Baixada Maranhense. As peças BR 0050 e CAB 007 (Figura 11) foram identificadas como $D$. primnolopha com base no focinho relativamente curto com narinas proeminentes, orelhas arredondadas bem destacadas, e olhos grandes e arredondados.

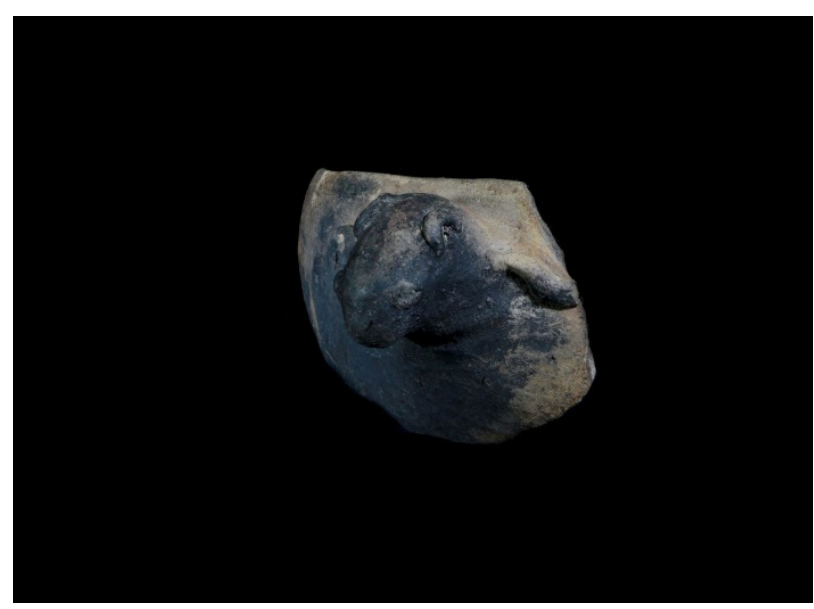

Figura 11. Capivara. Fotografia: Fábio Mata. 


\section{Família Sciuridae Fisher, 1817 \\ Quatipuru - Guerlinguetus brasiliensis (Gmelin, 1788)}

Guerlinguetus brasiliensis é a única espécie de quatipuru que ocorre na região que se estende do leste da Amazônia ao norte da Argentina, com registros na Baixada Maranhense (São Bento) e área próxima (Reserva Indígena Alto Turiaçu). A peça BR 0584 foi identificada como G. brasiliensis com base na morfologia do focinho, assim como nos grandes olhos e orelhas proeminentes.

\section{Questões}

A identificação de 13 espécies na cerâmica pré-colonial das estearias constitui uma contribuição substancial para o conhecimento sobre a diversidade de mamíferos na região da Baixada Maranhense. A diversidade representada é basicamente constituída de espécies pertencentes à fauna cinegética (tatus, porcos, capivaras, cutias, etc.) e à fauna carismática (carnívoros e primatas).

Uma das principais características da coleção arqueológica cerâmica das estearias é o uso de aplique modelado na parede ou lábio dos vasilhames. No Baixo Amazonas, apliques cerâmicos estão presentes também tanto na cultura Santarém (Gomes 2001) como na Marajoara (Roosevelt,1991). No entanto, elas são mais frequentes nas estearias e parece ter sido um traço tecnológico-cultural compartilhado por todas as aldeias. Dos seis sítios onde houve coleta de material, perfazendo uma área de 26 mil km², os apliques se fizeram presentes e compartilhavam os mesmos traços tecnológicos (Navarro 2018b).

Por que uma sociedade aquática representaria mais mamíferos que peixes em sua arte? A prévia análise da identificação das espécies demonstrou que os mamíferos representados na cultura material também habitam a área pantanosa da Baixada Maranhense. Neste sentido, os povos palafíticos estão em consonância com a ecologia da região. Mas por que mamíferos, para além da habitação em áreas de inundação? 
Prece ter havido uma cosmologia pan-amazônica centrada na importância dos mamíferos, desde o leste das terras baixas da América do Sul até às terras altas da Colômbia e Peru. Aqui, cosmologia é entendida como "the complete set of ideas about the nature and composition of the world or universe that is included in any given cultural system" (Weiss 1975:219).

Esta cosmologia da floresta também teria alcançado as terras altas dos Andes, uma vez que a iconografia Chavín, no Peru, caracterizada pela presença de onças, jacarés, macacos e anacondas, nitidamente tem conexão com a selva amazônica ao leste. A arte de Chavín retrata claramente a fauna das terras baixas, o que indica, portanto, que este importante centro urbano das terras altas participou desta grande área de interação cultural (Roe 1952). Na arte Mochica há imagens de homens transformando-se em onças, em contexto ritual com uso de alucinógenos (Kutscher 1954). Em San Agustín, nas terras altas colombianas, a iconografia revela a presença de onças cujas bocas têm caninos proeminentes (Reichel-Dolmatoff 1972). Pode ser que estas influências tenham chegado até mesmo à Mesoamérica, uma vez que as onças são o destaque na iconografia Olmeca, civilização que ocupou a costa do Golfo do México em 1500 a.C. (Grove 1972).

Para alguns autores (Viveiros de Castro 2002; Lima 1996; Gomes 2012) a importância dessa cosmologia tem a ver com o perspectivismo ameríndio, teoria que sustenta que todo ser vivo se diferencia por uma roupagem e que a condição de existência é a humanidade. Os animais foram homens, mas, ao desobedecer às divindades, foram transformados em seres inferiores. O perspectivismo, que se baseou em estudos mais antigos, como os de Furst (1968) e Grove (1972), está relacionado à ontologia da caça e do xamanismo: é o caçador que tem o contato com os animais e é o xamã responsável pelo contato espiritual entre homens e animais. Segundo Londoño Sulkin (2005) os animais tornaram-se agressores dos seres humanos, sobre os quais derramaram doenças, pragas e até mesmo a morte. É preciso manter, deste modo, o equilíbrio cosmológico destas forças antagônicas. Rei- 
chel-Dolmatoff (1972) considerou que são três as ações negativas que os animais têm sobre os humanos: a revanche dos animais por serem presas dos seres humanos (caça), as doenças provocadas pelos animais e a malevolência de seres sobrenaturais como o Mestre dos Animais.

Da necessidade de controle das forças naturais, o xamã emerge dentro de um contexto de poder. Assim, para Roe (1952), os mitos da floresta tropical da América do Sul têm uma cosmologia basal sustentada nos animais. Para este autor, houve uma esfera de interação cultural em toda a Amazônia. Por exemplo, Roe (1952) documentou mitos associados com mamíferos entre os Tupi, onde se destaca a onça, cuja pele queimada produzia cinzas usadas em processos de curetagem pelos pajés ou xamãs. Estes curandeiros podiam fazer viagens ao mundo aquático subterrâneo visitando o Goñanéêc, espírito das águas, um jaguar amarelo, que vivia em festa.

É o xamã quem media as ações da natureza na vida humana (Reichel-Dolmatoff 1972). Gomes (2012) publicou uma importante discussão teórica acerca do tema, mas nem ela, nem os formuladores teóricos do perspectivismo, centraram-se num ponto nevrálgico da teoria: é preciso ressaltar que nas relações míticas entre homens e animais, estes últimos, além de serem mamíferos, possuem características biológicas próprias de cada espécie, e assim atuam conforme esta especificidade.

Fizemos um levantamento associando os animais representados nos apliques cerâmicos das esterarias com os mitos coletados e discutidos pelos seguintes estudiosos: Roe (1952), Nimuendaju (1967), Elick (1969), Lévi-Strauss (1969, 1973), Reichel-Dolmatoff (1972), Hugh Jones (1974) e Kozác et al. (1979). O objetivo foi relacionar estes animais com características agenciais, i.e. culturais, próprias e seu papel mítico. Os resultados estão apresentados na tabela abaixo:

Das peças analisadas neste artigo, três delas são macacos. Um exemplar em especial, ARM 061 (Aotus infulatus ou macaco-da-noite) (Figura 6), chama a atenção. Na região umbilical do espécime existe uma circunferência artificial, isto é, uma depressão que foi confeccionada pelos indígenas. Entre os Karijona, um grupo indígena Karib 
da Colômbia, tinham por costume realizar rituais que consistiam em encher o corpo do inimigo com tabaco, que também era fumado, e depois reproduzir o cenário ritual dentro do corpo de um macaco (Dolmatoff 1972). Era um mito civilizador que mostrava a importância do ser humano sobre estes animais. Pois bem, este orifício umbilical do exemplar cerâmico analisado poderia representar a reprodução deste mito, destacando-se que a depressão poderia ter sido preenchida com tabaco e fumada através de inaladores (Porro 2010). Algumas vezes, caçadores capturavam macacos e os colocavam num poste central na aldeia para serem mortos e queimados na intenção de zombá-los, mostrando sua condição inferior à do ser humano. Macacos também estão associados à sujeira, à promiscuidade, à menstruação, ao canibalismo, ao barulho, ao trovão, à trapaça, ao riso, ao mundo subterrâneo e aquático, às flautas fálicas e à condição protohumana em vários mitos amazônicos (Reichel-Dolmatoff 1972).

Cachorros-do-mato também ocupam um papel importante nas mitologias da floresta tropical, estando associados à companhia humana. A terminologia 'cachorro do xamã' (Hugh-Jones 1974) é recorrente nos mitos tropicais e está relacionada ao jaguar, um animal que propicia a cura de enfermidades. O exemplar da coleção do LARQ, peça BR 0056 (Figura 9), parece estar em posição de ataque, com a cauda e as orelhas de pé, a mesma posição de um jaguar, revelando que poderia ser uma menção ao ato xamânico protetivo em ação.

Os porcos do mato (queixadas e caititus) são outros mamíferos importantes nas cosmologias indígenas da floresta tropical. Por causa do forte odor e do barulho que fazem estão associados ao ato libidinoso. Os Mundurucu acreditam que seres humanos promíscuos se transformaram nestes animais (Lévi-Strauss 1969). São, desse modo, símbolo de ações libidinosas da transformação do homem-animal para o homem-cultural. Segundo o mesmo autor, os caititus estão associados ao trovão entre os Tenehetehara, Tapirapé e Kayapó. Entre os Shipibo-Conibo são seres femininos em oposição ao jaguar, que os preda, evidenciando, portanto, um binômio de presa-predador/homem-mu- 
lher. Nimuendajú (1967) documentou um mito entre os Apinayé em que os porcos-do-mato são animais ligados ao mundo subterrâneo e, por extensão, aos espíritos da morte. As peças BR 0034 (Figura 10) e BR 10202 podem representar esses mitos.

O tatu é símbolo de útero entre os Kogi, povo indígena que vive na Serra Nevada de Santa Marta, na Colômbia, porque este animal cava a terra e penetra o mundo subterrâneo (Lévi-Strauss, 1973). Em alguns mitos, como entre os Barasana (Hugh-Jones, 1974), o tatu está associado à morte porque come os ossos daqueles que morreram. $\mathrm{Na}$ coleção das estearias há dois exemplares de tatus identificados, um tatu-canastra e um tatu-peba, ARM 10320 (Figura 2) e CAB 011 (Figura 3), respectivamente.

Outros mamíferos identificados na coleção arqueológica, como guaxinins e quatipurus, cutias e capivara também aparecem em mitos indígenas da Amazônia. Os guaxinins estão associados às atividades trapaceiras entre os Ka'apor Urubu do Maranhão (Roe,= 1952). A cutia está associada ao mundo aquático e ao mundo espiritual de nível inferior (Elick 1969). Capivaras também estão associadas ao mundo aquático e à morte (Kozác et al 1979) (Figura 11).

\section{Conclusão}

Os conceitos cosmológicos aqui apresentados evidenciam uma clara adaptação dos povos das estearias ao meio ambiente, uma vez que os animais participam ativamente da vida humana. Assim como demonstrou Reichel-Dolmatoff (1972) entre os Desana no noroeste amazônico da Colômbia, os povos das estearias construíram uma relação entre as estruturas míticas e os princípios ecológicos da Baixada Maranhense, uma região rica em mamíferos, a partir de mecanismos de controle social com características adaptativas com o objetivo de garantir o equilíbrio entre os recursos naturais disponíveis e as demandas da vida em sociedade. Não à toa, todos os mamíferos representados na coleção arqueológica estudada estão representados em mitos da floresta tropical. 
À luz da mitologia pan-amazônica, muitos mamíferos que povoam os mitos indígenas da floresta tropical foram caçados e serviram de alimento para os homens, como os porcos-do-mato e cutias. Seriam necessários, portanto, rituais para impedir a vingança destes animais. Possivelmente, eram realizados rituais que conectavam estas duas esferas vitais (homem/animais) e que se autorregulavam. Houve, portanto, uma intrínseca relação entre as cosmologias indígenas e a ecologia circundante aos espaços escolhidos para viver.

Chamam a atenção os aspectos negativos destes mamíferos, como a morte, espíritos malignos, mundo subterrâneo e aquático, sujeiras e atos de trapaça, o que poderia indicar que a decoração de apliques destes animais nas cerâmicas arqueológicas estaria associada a rituais cujo principal objetivo seria o de neutralizar estas qualidades contraproducentes e negativas para a sociedade. Neste sentido, ao trazer estes animais para dentro da aldeia, incorporando-os à sua cultura, os indígenas viam uma maneira de equilibrar seres/forças diferentes que conviviam em um mesmo ambiente lato sensu. Assim, a ecologia estava a serviço da cosmologia.

Este artigo também faz uma crítica às teorias do perspectivismo ameríndio (Viveiros de Castro 2002), que tendem a uniformizar os animais dentro de uma mesma categoria biológica a partir de sua roupagem. Este artigo evidencia que a relação entre biologia, arqueologia e mitologia enfatiza aspectos próprios determinados de acordo com a espécie animal. $\mathrm{O}$ estudo biológico das espécies pode, portanto, ser uma ferramenta essencial para a compreensão dos mitos indígenas, sua agência nas sociedades indígenas, função e sua relação com a produção de cultura material. Por outro lado, no que diz respeito às relações entre animais e homens, este artigo corrobora a associação enfatizada tanto pelo como pelo perspectivismo.

Antropólogos em geral estão de acordo que o perspectivismo é uma teoria xamânica em que pajés assumem a forma de animais, preferencialmente os predadores, sendo uma ontologia da caça. No entanto, é necessário aos estudiosos das Ciências Humanas saber exa- 
tamente quais os animais são presas e quais são predadores com o intuito de melhor entender a relação entre Homens e Animais. Este artigo demonstrou, também, que os animais noturnos escolhidos para serem representados na iconografia arqueológica, são, em geral, predadores e não presas. Portanto, é muito provável que se possa avançar nesta temática comparando estes predadores com a ação xamânica, seus sujeitos, modos de atuar e sua performance.

A maioria dos mamíferos estudados neste artigo como guaxinins, preguiças e tatus são animais predominantemente noturnos que, na mitologia amazônica, estão associados ao mundo aquático e da morte. Curiosamente, os animais menos representados na coleção arqueológica, como irara, quatipuru ou a cutia, são os mamíferos que menos aparecem representados nos apliques arqueológicos e os que menos povoam os mitos amazônicos. Talvez estes animais não demonstrassem perigo para a vida humana, o que explicaria sua pouca incidência na representação arqueológica. Salienta-se, novamente, a importância de representação de animais ameaçadores à vida humana, a ecologia, desse modo, sendo amplamente adaptativa, nesse contexto.

A escolha dos mamíferos como principais agentes míticos provavelmente repousa sobre o papel da caça, mesmo entre sociedades que aparentemente pouco se dedicou a esta atividade. Apesar de não haver documentação etnohistórica e relatos etnográficos referentes aos grupos de palafiteiros pré-coloniais no Maranhão, uma vez que esses grupos já haviam colapsado pelo menos quatrocentos anos antes da invasão europeia (a data mais recente obtida é o ano de 1140 d.C. em amostra datada de cerâmica do sítio Cabeludo), os mitos da floresta tropical aplicam-se muito bem a eles. Quase todas as espécies representadas nos apliques arqueológicos dos vasilhames cerâmicos estão associados aos mitos da floresta tropical. Estes mitos possuem uma base de história de longa duração. Roe (1952) parece estar certo a respeito dessa esfera de interação entre os grupos indígenas amazônicos.

Uma interpretação paralela ao papel preponderante dos mamíferos nestes mitos repousa na característica peculiar de grande parte 
destes animais viverem em solo e agirem na transformação do mesmo, como cavar buracos, que representaria o mundo subterrâneo e sua associação com a morte de grande parte dos mitos indígenas. Caberia estudar, num segundo momento, as formas dos vasilhames arqueológicos onde estes animais estão presentes com o intuito de verificar a possível relação entre a função das vasilhas e os mitos associados a estes recipientes. Seriam estes recipientes utilizados nos rituais que os mitos descrevem? É muito provável que sim.

Por outro lado, os estudos sobre as estearias podem corroborar a natureza dos mitos amazônicos, uma vez que estes sítios possuem material arqueológico bem preservado, como os apliques de animais. $\mathrm{O}$ meio lacustre onde estes grupos humanos viveram confirma, portanto, a natureza aquática, pertencente ao mundo subterrâneo, de vários dos animais que deram vida aos mitos tropicais tanto das terras altas como das terras baixas da América do Sul.

Por fim, é importante mencionar os frutíferos resultados da colaboração entre a Arqueologia e a Zoologia, uma vez que características biológicas importantes, percebidas pelos indígenas e transformadas em simbologias, passam, muitas vezes, despercebidas por arqueólogos e antropólogos, sendo interpretadas somente à luz da teoria da roupagem animal perspectivista. É necessário que os arqueólogos e antropólogos dialoguem mais com os zoólogos, pois os frutos serão profícuos.

\section{Referências:}

ADAM, P. J. 1999. "Choloepus didactylus". Mammalian Species, 621:1-8.

ALMEIDA, A. S. \& VIEIRA, I. C. G. 2010. "Centro de Endemismo Belém: Status da vegetação remanescente e desafios para conservação da biodiversidade e restauração ecológica”. Revista de Estudos Úniversitários, 36(3):95-111.

BALDWIN, J. D. \& BALDWIN, J. I. 2010. "The squirrel monkey, genus Saimiri”. In COIMBRA-FILHO, A. F. \& MITTERMEIER, R. A. (eds.): Ecology and behavior of Neotropical Primates, pp. 277-330. Rio de Janeiro: Academia Brasileira de Ciências. 
BALDWIN, J. D. 1985. "The behavior of squirrel monkey (Saimiri) in natural environments". In ROSENBLUM, L. A. \& COE, C. L. (eds.): Handbook of Squirrel Monkey Research, pp. 35-53. Nova York/Londres: Plenum Press.

BARRETO, Cristiana. 2008. Meios místicos de reprodução social: arte e estilo na cerâmica funerária da Amazônia Antiga. Tese de Doutorado. São Paulo: Universidade de São Paulo.

BEISIEGEL, B. M. \& CAMPOS, C. B. 2013. "Avaliação do risco de extinção do Quati Nasua nasua (Linnaeus, 1766) no Brasil". Biodiversidade Brasileira, 3(1):269-276.

BONVICINO, C. R. \& OLIVEIRA, J. A. 2006. "Ordem Rodentia”. In REIS, N. R. et al. (eds.): Mamíferos do Brasil, pp. 347-400. Londrina: Paraná.

BONVINCINO, C.R.; OLIVEIRA, J.A. \& D'ANDREA, P.S. 2008. Guia dos Roedores do Brasil, com Chaves para Gêneros Baseadas em Caracteres Externos. Rio de Janeiro: Centro Pan-Americano de Febre Aftosa - OPAS/OMS.

CARDOSO DA SILVA, J. M. \& OREN, D. C. 1996. "Application of parsimony analysis of endemicity in Amazonian biogeography: An example with primates". Biological Journal of the Linnean Society, 59:427-437.

CARDOSO DA SILVA, J. M.; RYLANDS, A. B. \& FONSECA, G. A. B. 2005. "O destino das áreas de endemismo da Amazônia". Megadiversidade, 1(1):124131.

CATZEFLIS, F. et al. 2013. Dasyprocta prymnolopha, 2008. IUCN Red List of Threatened Species. Version 2013.2. (www.iucnredlist.org; acesso em 30/12/2013).

CHEIDA, C. C.; GUIMARÃES, C. H. \& BEISIEGEL, B. M. 2013. "Avaliação do risco de extinção do Guaxinim Procyon cancrivorus (Cuvier, 1798) no Brasil". Biodiversidade Brasileira, 3(1):283-290.

CHEIDA, C. C. et al. 2006. "Ordem Carnivora". In REIS, N. R. et al. (eds.): Mamíferos do Brasil, pp. 231-275. Londrina:Editora da Universidade Estadual de Londrina.

CHIARELLO, A. \& PLESE, T. 2018. Choloepus didactylus. The IUCN Red List of Threatened Species. (http://dx.doi.org/10.2305/IUCN.UK.2014-1.RLTS. T4777A47439542.en; acesso em 19/04/2018).

CHIAREllo, A. G. et al. 2015. Avaliação do Risco de Extinção de Priodontes maximus (Kerr, 1792) no Brasil. Processo de avaliação do risco de extinção da fauna brasileira. ICMBio. (www.icmbio.gov.br/portal/biodiversidade/ fauna-brasileira/lista-de-especies/7014-priodontes-maximus.html; acesso em 19/04/2018).

CRACRAFT, J. 1985. "Historical biogeography and patterns of differentiation within the South American avifauna: areas of endemism". Ornithological monographs, 36:35-84.

CUARÓN, A.D. ET al. 2016. Eira barbara. The IUCN Red List of Threatened Species. e.T41644A45212151. (http://dx.doi.org/10.2305/IUCN.UK.20161.RLTS.T41644A45212151.en; acesso em 01/04/2018). 
DeMATTEO, K.; MICHALSKI , F. \& LEITE-PITMAN, M. . 2015.

Speothos venaticus. The IUCN Red List of Threatened Species 2011: e.T20468A9203243. (http://dx.doi.org/10.2305/IUCN.UK.2011-2.RLTS. T20468A9203243.en; acesso em 19/04/2018).

DUNNUM, J. L. 2015. "Family Caviidae G. Fischer, 1817”. In PATTON, J., PARDINAS, U. \& D’ELÍA, G. (eds.): Mammals of South America, pp. 690726. Chicago/ London: The University of Chicago Press.

EISENBERG, J. F. \& REDFORD, K. H. 1999. Mammals of the Neotropics - The Central Neotropics. Chicago: University of Chicago Press.

ELICK, John W. 1969. An Ethnography of the Pichis Valley Campa of Eastern Peru. Ph.D. Dissertation. Los Angeles: University of California.

EMMONS, L. \& FEER, F. 1997. Neotropical rainforest mammals: A field guide. Chicago: The University of Chicago Press.

EMMONS, L. \& HELGEN, K. 2008. Nasua nasua. IUCN 2013. IUCN Red List of Threatened Species. Version 2013.1. (www.iucnredlist.org; acesso em 20/11/2013).

FURST, Peter T. 1968. "The Olmec Were-Jaguar Motif in the Light of Ethnographic Reality". In BENSON, E. (ed.): Dumbarton Oaks Conference on the Olmec, pp. 143-174. Washington: Dumbarton Oaks Research Library and Collections.

GARDNER, A. L. 2005. “Order Cingulata”. In WILSON, D. \& REEDER, D. (eds.): Mammal Species of the World, a Taxonomic and Geographic Reference, pp. 94-99. Baltimor: The Johns Hopkins University Press.

. 2007. "Order Pilosa Flower 1883". In GARDNER, A. L. (ed): Mammals of South America, pp.157-164. Chicago: The University of Chicago Press.

GARDNER, A. L. \& NAPPLES, V. L. 2007. "Family Megalonychidae P. Gervais, 1855”. In GARDNER, A. L. (ed): Mammals of South America, pp. 165-168. Chicago: The University of Chicago Press.

GELL, Alfred. 1998. Art and agency: an anthropological theory. Oxford: Clarendon Press.

GOLDMAN, Irving. 1963. The Cubeo: Indians of the Nortwest Amazon. Urbana: University of Illinois Press.

GOMES, Denise. 2012. "O perspectivismo ameríndio e a ideia de uma estética americana”. Bol. Museu. Paraense Emílio Goeldi, 7(1):133-159.

. 2001. "Santarém: symbolism and power in the tropical forest". In McEWAN, C. et al. (eds.): The Unknown Amazon. Culture and Nature in Ancient Brazil, pp. 134-155. Londres: The British Museum Press.

GROVE, David C. 1972. "Olmec Felines in Highland Central Mexico. The Cult of the Feline: A Conference in Pre-Columbian Iconography". In BENSON, E. (ed.): Dumbarton Oaks Conference on the Olmec, pp. 153-164. Washington: Dumbarton Oaks Research Library and Collections.

GRUBB, P. 2005. "Order Artiodactyla". In WILSON, D. \& REEDER, D. (eds.): Mammal Species of the World, a Taxonomic and Geographic Reference, pp. 637722. Baltimor: The Johns Hopkins University Press. 
HERSHKOVITZ, P. 1983. "Two new species of night monkeys, genus Aotus (Cebidae, Platyrrhini): a preliminary report on Aotus taxonomy”. American Journal of Primatology, 4:209-243.

HILL, W. C. O. 1960. Primates, comparative anatomy and taxonomy. Edinburgh: Edinburgh University Press.

HODDER, Ian. 1982. Symbols in action. Cambridge: Cambridge University Press.

HUGH-JONES, Stephen. 1974. Barasana Initiation: Male Initiation and Cosmology among the Barasana Indians of the Vaupés Area of Colombia. Ph.D. Dissertation. Cambridge: Cambridge University.

IACK-XIMENES, G. E. 1999. Sistemática da família Dasyproctidae Bonaparte, 1838 (Rodentia, Histricognathi) no Brasil. Dissertação de Mestrado. São Paulo: Universidade de São Paulo.

JORGE, R. P. S. et al. 2013. "Avaliação do estado de conservação do Cachorrovinagre Speothos venaticus (Lund, 1842) no Brasil”. Biodiversidade Brasileira, 3(1):179-190.

KOZÁK, V. et al. 1979. "The Héta Indians: Fish in a Dry Pond”. Anthropological Papers, 55(6):351-434.

KUTSCHER, Gerdt. 1950. "Iconographic Studies as an Aid in the Reconstruction of Early Chimu Civilization”. In ROWE, J. \& MENZEL, D. (eds.): Peruvian Archaeology: Selected Readings, pp.115-124. Palo Alto: Peek Publications.

LAGROU, Els. 2007. A fluidez da forma: arte, alteridade e agência em uma sociedade amazônica (Kaxinawa, Acre). Rio de Janeiro: Topbooks.

LEITE FILHO, D. 2016. "Arqueologia dos ambientes lacustres: cultura material, dinâmica sociocultural e sistema construtivo nas estearias da Baixada Maranhense". Arquivos do Museu de História Natural e Jardim Botânico, 25(1):54-99.

LÉVI-STRAUSS, Claude. 1969. The Raw and the Cooked: Introduction to a Science of Mythology 1. New York: Harper \& Row.

. 1973. From Honey to Ashes: Introduction to a Science of Mythology 2. New York: Harper \& Row.

LIMA, Tania Stolze. 1996. "O dois e seu múltiplo: reflexões sobre o perspectivismo em uma cosmologia tupi". Mana, 2(2):21- 47.

LONDOÑO SULKIN, Carlos D. 2005. "Inhuman beings: morality and perspectivism among Muinane People (Colombian Amazon)”. Ethnos, 70(1):7-30.

LOPES, Raimundo. 1924. "A civilização lacustre do Brasil”. Boletim do Museu Nacional, 1(2):87-109.

MARINHO-FILHO, J. \& MEDRI, I. M. 2008. "Priodontes maximus (Kerr, 1792)". In MACHADO, A. et al. (eds.): Livro Vermelho da Fauna Brasileira Ameaçada de Extinção, pp. 707-709. Brasília/ Belo Horizonte: MMA/ Fundação Biodiversitas.

MEDRI, I.; MOURÃO, G. M. \& RODRIGUES, F. H. G. 2006. “Ordem Xenarthra”. In REIS, N. R. et al. (eds.): Mamíferos do Brasil, pp. 707-709. Londrina: Editora da Universidade Estadual de Londrina. 
MIRANDA, F. R.; RÖHE, F. \& VAZ, S. M. 2015. Avaliação do Risco de Extinção de Choloepus didactylus (Illiger, 1811) no Brasil. Processo de avaliação do’ risco de extinção da fauna brasileira. ICMBio. (www.icmbio.gov.br/portal/ biodiversidade/fauna-brasileira/lista-de-especies/7124-mamiferos-choloepusdidactylus-preguica-real.html; acesso em 10/09/2016).

NAVARRO, Alexandre. 2018a. "New evidence for late first-millennium AD stilthouse settlements in Eastern Amazonia". Antiquity, 92(366):1586-1603. . 2018b. "Morando no meio de rios e lagos: mapeamento e análise cerâmica de quatro estearias do Maranhão". Revista de Arqueologia, 31(1):73103.

. 2013. "O povo das águas: carta arqueológica das estearias da porção centro-norte da Baixada Maranhense". Caderno de Pesquisas, 20(3):1-8.

NAVARRO, A. G. et al. 2017. "O muiraquitã da estearia da Boca do Rio, Santa Helena, Maranhão: estudo arqueológico, mineralógico e simbólico”. Boletim do Museu Paraense Emílio Goeldi, 12(3):869-894.

NIMUENDAJÚ, C. 1967. The Apinayé. Netherlands: Oosterhout N.B. . 1941. Mapa etno-histórico do Brasil e regiões adjacentes. Rio de Janeiro: IBGE.

OLIVEIRA, T. G. et al. 2011. "Mamíferos da Amazônia maranhense". In MARTINS, M. \& OLIVEIRA, T. (eds.): Amazônia Maranhense: Diversidade e Conservação, pp.251-270. Belém: MPEG.

OLIVEIRA, T. G.; GERUDE, R. G. \& SILVA-JÚNIOR, J. S. 2007. "Unexpected mammalian records in the state of Maranhão". Boletim do Museu Paraense Emílio Goeldi, 2(2):23-32.

PATTON, D. L. \& EMMONS, L. H. 2015. "Family Dasyproctidae Bonaparte, 1838”. In PATTON, J., PARDIÑAS, U. \& D’ELÍA, G. (eds.): Mammals of South America, pp. 733-762. Chicago/ London: The University of Chicago Press.

PINE, R. H. 1973. "Mammals (exclusive of bats) of Belém, Pará, Brazil”. Acta Amazônica, 3:47-79.

PINTO, T. et al. 2015. Avaliação do Risco de Extinção de Aotus infulatus (Kühl, 1820) no Brasil. Processo de avaliação do risco de extinção da fauna brasileira. ICMBio. (www.icmbio.gov.br/portal/biodiversidade/faunabrasileira/estado-de-conservacao/7160-mamiferos-aotus-infulatus-macaco-danoite.html; acesso em 15/03/2016).

PORRO, Antonio. 2010. "Arte e simbolismo xamânico na Amazônia". Boletim do Museu Paraense Emílio Goeldi, 5(1):129-144.

PRESLEY, S. J. 2010. "Eira Barbara”. Mammalian Species, 636:1-6.

REICHEL-DOLMATOFF, G. 1976. "Cosmology as Ecological Analysis: A View from the Rain Forest”. Man, 11:307-318.

. 1972. "The Cultural Context of an Aboriginal Hallucinogen:

Banisteriopsis Caapi”. In FIRST, P. (ed.): Flesh of the Gods: The Ritual Use of Hallucinogens, pp. 84-113. New York: Praeger. 
REID, F., HELGEN, K. \& GONZÁlEZ-MAYA, J. F. 2016. Procyon cancrivorus. The IUCN Red List of Threatened Species e.T41685A45216426. (dx.doi. org/10.2305/IUCN.UK.2016-1.RLTS.T41685A45216426.en; acesso em 19/04/2018).

RODRIGUES, L., PONTES, A. \& ROCHA-CAMPOS, C. 2013. "Avaliação do risco de extinção da Irara Eira barbara (Linnaeus, 1758) no Brasil”. Biodiversidade Brasileira, 3(1):195-202.

ROE, P. G. 1982. The cosmic zygote: cosmology in the Amazon Basin. New Brunswick: Rutgers University Press.

ROOSEVELT, Anna C. 1991. Moundbuilders of the Amazon: Geophysical Archaeology on Marajo Island, Brazil. San Diego, Academic Press.

. 1988. "Interpreting Certain Female Images in Prehistoric Art". In MILLER, V. (ed.): The Role of Gender in Precolumbian Art and Architecture, pp. 1-34. Lanham: Press of America.

SCHAAN, Denise P. 2004. The Camutins Chiefdom. Rise and development of complex societies on Marajó Island, Brazilian Amazon. Tese de Doutorado. Pittsburgh: Pittsburgh University.

SILVA-JÚNIOR, J. S. et al. 2015. Avaliação do Risco de Extinção de Saimiri collinsi Osgood, 1916 no Brasil. Processo de avaliação do risco de extinção da fauna brasileira. ICMBio. (www.icmbio.gov.br/portal/biodiversidade/ fauna-brasileira/estado-de-conservacao/7264-mamiferos-saimiri-collinsimacaco-de-cheiro.html; acesso em 10/01/2016).

SILVA, K. et al. 2015. Avaliação do Risco de Extinção de Euphractus sexcinctus Linnaeus, 1758 no Brasil. Processo de avaliação do risco de extinção da fauna brasileira. ICMBio. (www.icmbio.gov.br/portal/ biodiversidade/fauna-brasileira/lista-de-especies/7109-mamiferos-euphractussexcinctus-tatu-peba.html; acesso em 02/10/2016).

SILVA-JÚNIOR, J. S. \& NUNES, A. P. 2001. "The disjunct geographical distribution of the yellow-armadillo, Euphractus sexcinctus (Xenarthra, Dasypodidae)". Edentata, 4:16-18.

SILVA-JÚNIOR, J. S., FERNANDES, M. \& CERQUEIRA, R. 2001. "New records of the yellow-armadillo (Euphractus sexcinctus) in the state of Maranhão, Brazil (Xenarhtra, Dasypodidae)”. Edentata, 4:18-23.

SILVA-JÚNIOR, J. S., NUNES, A. P. \& FERNANDES, M.. 1995. "Geographic distribution of night monkeys Aotus, in Northern Brazil: new data and a correction”. Neotropical Primates, 2(3):72-74.

SILVA-JÚNIOR, J. S. et al. 2010. "Mamíferos terrestres de médio e grande porte no litoral da Amazônia brasileira”. In PESSÔA, L., TAVARES, W. \& SICILIANO, S. (eds.): Mamíferos das Restingas e Manguezais do Brasil, pp. 1944. Rio de Janeiro: Sociedade Brasileira de Mastozoologia.

SILVA-JÚNIOR, J. S. \& FERNANDES, M. E. B. 1999. “A northeastern extension of the distribution of Aotus infulatus in Maranhão, Brazil”. Neotropical Primates, 7(3):76-80. 
STONE, A. I. et al. 2009. "Non-volant mammalian diversity in fragments in extreme eastern Amazonia”. Biodiversity and Conservation, 18:1685-1694.

TIEPOLO, L. M. \& TOMAS, W. M. 2006. "Ordem Artiodactyla”. In REIS, N. R. et al. (eds.): Mamíferos do Brasil, pp. 283-303. Londrina: Editora da Universidade Estadual de Londrina.

TRINCA, C., PALMEIRA, F. \& SILVA-JÚNIOR, J. S. 2006. "A southern extension of the geographic distribution of the two-toed sloth, Choloepus didactylus (Xenarthra, Megalonychidae)". Edentata, 7:7-9.

VIVEIROS DE CASTRO, Eduardo. 2002. A Inconstância da alma selvagem. São Paulo: Cosac \& Naify.

WEISS, Gerald. 1975. "Campa Cosmology: The World of a Forest Tribe in South America”. American Museum of Natural History, 52(5):219-588.

WETZEL, R. M. et al. 2007. "Order Cingulata Illiger, 1811". In GARDNER, A. L. (ed): Mammals of South America, pp. 128-157. Chicago: The University of Chicago Press.

WRIGHT, P. C. "The night monkeys, genus Aotus. 1981". In COIMBRAFILHO, A. \& MITTERMEIER, R. (eds.): Ecology and behavior of Neotropical Primates, pp. 211-240. Rio de Janeiro: Academia Brasileira de Ciências.

XAVIER, G. et al. 2015. Avaliação do Risco de Extinção de Bradypus variegatus Schinz, 1825 no Brasil. Processo de avaliação do risco de extinção da fauna brasileira. ICMBio. (www.icmbio.gov.br/portal/ biodiversidade/fauna-brasileira/lista-de-especies/7116-mamiferos-bradypusvariegatus-preguica-comum.html; acesso em 07/01/2016).

\begin{abstract}
Amerindian societies have been involved in complex adaptive and cosmological systems, whose myths are populated by animals of the most diverse species. However, the relation between these animals and archaeological materials was not explored. This article presents a collection of artifacts from the Maranhão stilt villages with the representation of animals that were identified through their biological attributes at the species level and then compared with their social functions from Pan Amazonian myths. One of the results is a critique of Amerindian perspectivism, since indigenous people who inhabited the pre-colonial stilts villages from Maranhão were concerned with identifying the different species of their ecological niche. It is also proposed that Zoology is indispensable for the study of animal representation in archaeological artifacts.
\end{abstract}

Keywords: Material culture, Amazonian myths, Stilt villages from Maranhão, Amerindian perspectivism. 


\section{Anexo:}

\begin{tabular}{|c|c|c|c|}
\hline MAMÍFERO & PEÇA/SÍTIO & HÁBITOS & $\begin{array}{l}\text { Q UA L I D A D E S / M I T O S / } \\
\text { AGENCIA }\end{array}$ \\
\hline $\begin{array}{l}\text { Tatu-canastra } \\
\text { e Tatu-peba }\end{array}$ & $\begin{array}{l}\text { ARM } 10320 \text { e } \\
\text { CAB 011 Sítios } \\
\text { Armíndio e } \\
\text { Caboclo }\end{array}$ & $\begin{array}{l}\text { Noturno/predador } \\
\text { Diurno/noturno/predador }\end{array}$ & $\begin{array}{l}\text { Útero, cova, mundo subterrâneo, } \\
\text { comedor de ossos, morte. }\end{array}$ \\
\hline $\begin{array}{l}\text { Preguiça-de- } \\
\text { ben tin ho, } \\
\text { Preguiça-real, } \\
\text { M a c a o- } \\
\text { de-cheiro e } \\
\text { Macaco-da- } \\
\text { noite }\end{array}$ & $\begin{array}{l}\text { ARM } 271 \text { e } \\
\text { ARM 10388, } \\
\text { BR 001 e ARM } \\
\text { 061 Sítios } \\
\text { Armíndio e } \\
\text { Boca do Rio }\end{array}$ & $\begin{array}{l}\text { Noturno/presa } \\
\text { Noturno/presa } \\
\text { Diurno/predador/presa } \\
\text { Noturno/crepuscular/ } \\
\text { predador/presa }\end{array}$ & $\begin{array}{l}\text { Mito civilizador, trapaceiros, macaco } \\
\text { libidinoso associado à menstruação, } \\
\text { mundo subterrâneo, mundo } \\
\text { aquático, canibal, riso, barulhento, } \\
\text { trovão, flautas fálicas, produtor } \\
\text { de sujeira, lascivo, sexo, fumo, } \\
\text { alucinógenos, proto-humanos. }\end{array}$ \\
\hline Irara & BR 10311 & Diurno/noturno/predador & $?$ \\
\hline Quati & $\begin{array}{l}\text { BR } 0032 \text { e BR } \\
10215 \text { Sítio } \\
\text { Boca do Rio }\end{array}$ & Diurno/predador/presa & $?$ \\
\hline $\begin{array}{l}\text { Cachorro-do- } \\
\text { mato-vinagre }\end{array}$ & $\begin{array}{l}\text { BR } 0056 \text { Sítio } \\
\text { Boca do Rio }\end{array}$ & Diurno/predador & $\begin{array}{l}\text { "Cachorro do xamã", cura } \\
\text { enfermidades, protetor. }\end{array}$ \\
\hline $\begin{array}{l}\text { Guaxinim e } \\
\text { quatipuru }\end{array}$ & $\begin{array}{l}\text { JEN } 004 \text { e BR } \\
\text { 0584 Sítios } \\
\text { Jenipapo e } \\
\text { Boca do Rio }\end{array}$ & $\begin{array}{l}\text { Noturno/predador } \\
\text { Diurno/presa }\end{array}$ & Trapaceiros. \\
\hline $\begin{array}{l}\text { Porco-d o- } \\
\text { mato }\end{array}$ & $\begin{array}{l}\text { BR } 0034 \text { e BR } \\
10202 \text { Sítio } \\
\text { Boca do Rio }\end{array}$ & $\begin{array}{l}\text { D i u r no / n o t u r no / } \\
\text { predador/presa }\end{array}$ & $\begin{array}{l}\text { Ato libidinoso, mundo subterrâneo, } \\
\text { morte, trovão, promiscuidade. }\end{array}$ \\
\hline Cutia & $\begin{array}{l}\text { BR } 0050 \text { e } \\
\text { CAB } 007 \\
\text { Sítios Boca do } \\
\text { Rio e Caboclo }\end{array}$ & Diurno/crepuscular/presa & $\begin{array}{l}\text { Mundo espiritual inferior, mundo } \\
\text { aquático. }\end{array}$ \\
\hline Capivara & $\begin{array}{l}\text { ARM } 059 \text { Sítio } \\
\text { Armíndio }\end{array}$ & Diurno/presa & $\begin{array}{l}\text { Mundo subterrâneo, morte, ato } \\
\text { libidinoso, trovão, inimigo do } \\
\text { jaguar. }\end{array}$ \\
\hline
\end{tabular}

Recebido em Maio de 2019. Aprovado em Dezembro de 2019. 